\title{
Pulmonary Langerhans cell histiocytosis
}

\author{
Mehmet Kose • Mehmet Akif Ozdemir
}

Received: 2 April 2013 / Accepted: 24 April 2013 /Published online: 10 May 2013

(C) Springer-Verlag Berlin Heidelberg 2013

\begin{abstract}
Herein, we described 16-year-old boy with pulmonary cysts in both lung fields and diagnosed as isolated pulmonary Langerhans cell histiocytosis.
\end{abstract}

Keywords Langerhans cell histiocytosis · Langerhans cells · Lung cysts

A 16-year-old boy was admitted with decreased exercise tolerance. On examination, he had diminished respiratory sounds in both lung fields. Past history revealed that he was diagnosed as exercise-induced asthma 2 years ago and treated with budenoside for 2 years. His exertional dyspnea increased progressively. Chest X-ray revealed cystic changes in both lungs and subsequent diffuse reticular opacities produced by the overlapping cysts and thin-walled lung cysts (Fig. 1). Computed tomography scan also showed multiple thinwalled lung cysts (Fig. 2), in all lung fields. A skeletal X-ray survey and abdominal ultrasonography were normal. Bone marrow aspiration revealed no Langerhans cells. Open lung biopsy performed and histologic evaluation demonstrated nodular aggregates of Langerhans cells surrounded by dense infiltrates of eosinophils and lymphocytes. Immunohistochemical staining was strongly positive for CD1a. Pulmonary Langerhans cell histiocytosis was diagnosed. Treatment was started with prednisone.

\footnotetext{
M. Kose ( $\square)$

Division of Pediatric Pulmonology Unit, Department of Pediatrics, School of Medicine, Erciyes University, 38000 Kayseri, Turkey

e-mail: mhmtkose@yahoo.com
}

\section{A. Ozdemir}

Division of Haematology and Onchology, Department of Pediatrics, Erciyes University, Kayseri, Turkey

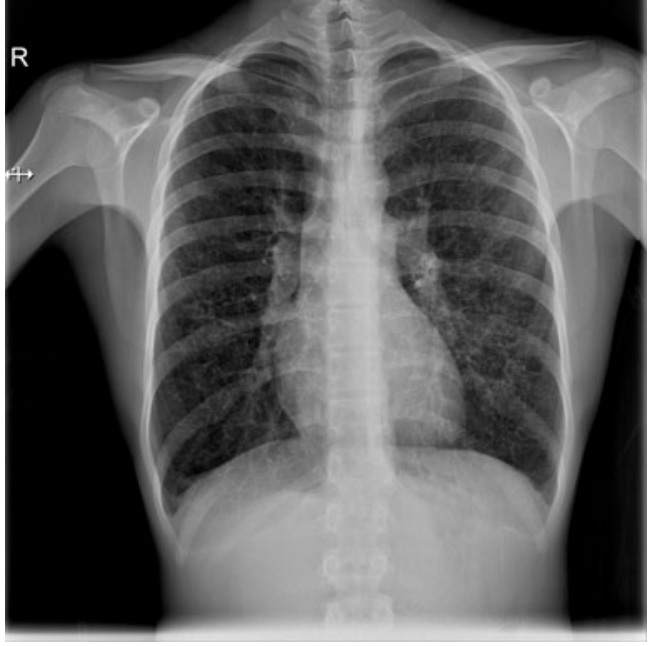

Fig. 1 Chest X-ray image showing cystic changes in both lungs and subsequent diffuse reticular opacities

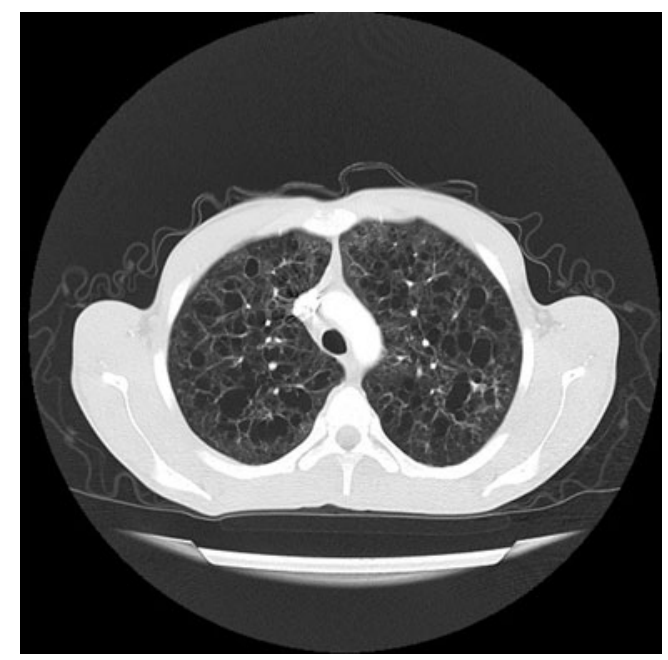

Fig. 2 CT scan showing multiple thin-walled lung cysts 